\title{
LIGHT, A Novel Ligand for Lymphotoxin $\beta$ Receptor and TR2/HVEM Induces Apoptosis and Suppresses In Vivo Tumor Formation Via Gene Transfer
}

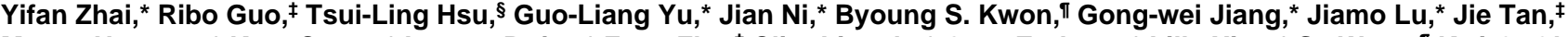 \\ Meena Ugustus, ${ }^{*}$ Kent Carter, ${ }^{*}$ Lorena Rojas, ${ }^{*}$ Feng Zhu, ${ }^{\star}$ Clint Lincoln, ${ }^{*}$ Greg Endress, ${ }^{*}$ Lilly Xing, ${ }^{*}$ Sa Wang, ${ }^{\pi}$ Kwi-O. Oh, \\ Reiner Gentz, ${ }^{\star}$ Steve Ruben, ${ }^{*}$ Marc E. Lippman, ${ }^{\ddagger}$ Shie-Liang Hsieh, ${ }^{\S}$ and Dajun Yang ${ }^{\ddagger}$ \\ *Human Genome Sciences, Inc., Rockville, Maryland 20850; ${ }^{\ddagger}$ Lombardi Cancer Center, Georgetown University Medical Center, \\ Washington, DC 20007; ${ }^{\S}$ Department of Microbiology and Immunology, National Yang-Ming University School of Medicine, Taipei, \\ Taiwan 112, ROC; ${ }^{\mathbb{D}}$ Department of Microbiology and Immunology, Indiana University, School of Medicine, Indianapolis, Indiana 46202
}

\begin{abstract}
LIGHT is a new member of tumor necrosis factor (TNF) cytokine family derived from an activated $T$ cell cDNA library. LIGHT mRNA is highly expressed in splenocytes, activated $\mathrm{PBL}, \mathrm{CD8}^{+}$tumor infiltrating lymphocytes, granulocytes, and monocytes but not in the thymus and the tumor cells examined. Introduction of LIGHT cDNA into MDA-MB-231 human breast carcinoma caused complete tumor suppression in vivo. Histological examination showed marked neutrophil infiltration and necrosis in LIGHT expressing but not in the parental or the Neo-transfected MDA-MB-231 tumors. Interferon $\gamma$ (IFN $\gamma$ ) dramatically enhances LIGHT-mediated apoptosis. LIGHT protein triggers apoptosis of various tumor cells expressing both lymphotoxin $\beta$ receptor (LT $\beta R$ ) and TR2/HVEM receptors, and its cytotoxicity can be blocked specifically by addition of a LT $\beta$ R-Fc or a TR2/HVEM-Fc fusion protein. However, LIGHT was not cytolytic to the tumor cells that express only the LT $\beta$ R or the TR2/HVEM or hematopoietic cells examined that express only the TR2/HVEM, such as PBL, Jurkat cells, or $\mathrm{CD8}^{+}$TIL cells. In contrast, treatment of the activated PBL with LIGHT resulted in release of IFN $\gamma$. Our data suggest that LIGHT triggers distinct biological responses based on the expression patterns of its receptors on the target cells. Thus, LIGHT may play a role in the immune modulation and have a potential value in cancer therapy. (J. Clin. Invest. 1998. 102:1142-1151.) Key words: TNF • breast cancer • apoptosis • LT $\beta$ R $・$ TR2/HVEM
\end{abstract}

\section{Introduction}

Members of the tumor necrosis factor $(\mathrm{TNF})^{1}$ family play important roles in cell activation, proliferation, differentiation,

Y. Zhai, S.-L. Hsieh, and D. Yang share senior authorship.

Address correspondence to Dajun Yang, Lombardi Cancer Center, Georgetown University Medical Center, 3970 Reservoir Rd., Washington, DC 20007. E-mail: yangd@gunet.georgetown.edu

Received for publication 20 March 1998 and accepted in revised form 20 July 1998

1. Abbreviations used in this paper: FISH, fluorescence in situ hybridization; RT-PCR, reverse-transcription PCR; sLIGHT, soluble LIGHT protein; TIL, tumor infiltrating lymphocytes; TRAF, TNFassociated factor.

J. Clin. Invest.

(C) The American Society for Clinical Investigation, Inc. 0021-9738/98/09/1142/10 \$2.00

Volume 102, Number 6, September 1998, 1142-1151

http://www.jci.org apoptosis, IG class switch, immune evasion, and immune suppression (1-6). Recently, the list of molecules belonging to the TNF receptor superfamily has expanded significantly. The discovery of DR3 (7), DR4 (8), DR5 (9), TRID (10), TR2 (HVEM, ATAR; 11-13), and OPG (14) indicated that there are a number of additional signal transduction pathways that lead to activation or programmed cell death (apoptosis) of cells. One new ligand molecule of the TNF family, TRAIL/ Apo2L (15-16), was reported very recently. Several TRAIL receptors (DR4, DR5, and TRID/DcR1) have recently been identified (8-10). The remarkable progress in identifying these new members of TNF ligand and TNFR family together with the studies on their signal transduction pathways has opened up novel molecular targets for the treatment of cancer and inflammatory diseases.

By searching an expressed sequence tag database (17), a new member of the TNF cytokine family was identified, named LIGHT, and was characterized as a cellular ligand for the TR2, which also names as herpes virus entry mediator (TR2/HVEM) and LT $\beta R$ (18). LT $\beta$ R is prominent on epithelial cells but is absent in $\mathrm{T}$ and $\mathrm{B}$ lymphocytes. Signaling via LT $\beta R$ triggers cell death in some adenocarcinomas $(19,20)$, whereas TR2/HVEM is a new member of TNFR family involved mainly in T cell activation (11). Here, we report the biological characterization of this novel TNF ligand. LIGHT is highly expressed in activated PBL, TIL, lymphocytes, granulocytes, and monocytes. A soluble LIGHT inhibits proliferation of various tumor cells. The inhibitory effect was dramatically enhanced in the presence of IFN $\gamma$ and can be blocked specifically by addition of a soluble LT $\beta$ R-Fc or TR2/HVEM-Fc fusion protein. Local production of LIGHT via gene transfer caused tumor suppression in vivo as demonstrated in human xenograft tumor models. Our data suggest that LIGHT produced by activated lymphocytes could evoke immune modulation from hematopoietic cells, which only express TR2/ HVEM, and induce apoptosis of tumor cells, which express both LT $\beta$ R and TR2/HVEM receptors.

\section{Methods}

Cells and reagents. Human breast cell lines (MCF-7, BT474, T47D, MDA-MB-134, and MCF10A), prostate cancer lines (PC-3 and LNCaP), human colon cancer lines (HT-29 and SW480), and human $\mathrm{T}$ cell Leukemia Jurkat cells were obtained from the American Type Culture Collection (ATCC, Rockville, MD). The human breast carcinoma MDA-MB-231, a subclone 2LMP, obtained from in vivo passage of MDA-MB-231 cells in nude mice was used in all of the experiments. Human melanoma antigen-reactive $\mathrm{CD}^{+} \mathrm{T}$ cell lines, TIL1200 and TIL1235 (21) was kindly provided by Dr. Y. Kawakami (National Cancer Institute, Bethesda, MD). All tumor cell lines were grown and maintained in the appropriate growth medium recommended by ATCC. Human PBMC were obtained from normal do- 
nors and were purified using Ficoll-Hypaque methods. PBMC were cultured in Aim- $\mathrm{V}$ medium containing 10\% human serum, in the absence or presence of $10 \mathrm{U} / \mathrm{ml}$ rIL-2 plus anti-CD3 mAb (10-100 ng/ $\mathrm{ml}$ ) for $3 \mathrm{~d}$. Purified $\mathrm{CD}^{+}, \mathrm{CD}^{+}{ }^{\mathrm{T}}$ lymphocytes, granulocytes, and macrophages were prepared using protocols described previously in Current Protocols in Immunology and were confirmed by FACS analysis. Jurkat cells were activated with the addition of anti-CD3 mAb (10-100 ng/ml). Anti-Fas mAb CH-11 was obtained from UBI (Lake Placid, NY). IFN $\gamma$ was obtained from Biosource International (Camarillo, CA).

Chromosome mapping of LIGHT gene. A 2-kb LIGHT cDNA was nick-translated using Digoxigenin-11-dUTP (Boehringer Mannheim, Indianapolis, IN) and fluorescence in situ hybridization (FISH) was carried out as detailed previously (22). Individual chromosomes were counterstained with DAPI and color digital images, containing both DAPI and gene signal detected with Rhodamine, were recorded using a triple-band pass filter set (Chroma Technology, Inc., Brattleboro, VT) in combination with a cooled charge coupled-device camera (Photometrics, Inc., Tucson, AZ) and variable excitation wave length filters (23). Images were analyzed using the ISEE software package (Inovision Corp., Durham, NC).

Reverse transcription-PCR analyses. Total RNA was prepared using Qiagen RNA kit (Qiagen, Chatsworth, CA). RNA was converted to cDNA by reverse transcription and amplified for 35 cycles by PCR following the manufacturer's instructions. Primers used for amplification of the LIGHT fragment are according to the sequence of LIGHT (18). GAPDH was used as an internal control for RNA integrity and equal gel loading. PCR products were run on a $1.5 \%$ agarose gel stained with ethidium bromide and visualized by UV illumination.

Retroviral transduction of tumor cells. A retroviral vector PG1SamEN (a kind gift from Dr. P. Hwu, National Cancer Institute) was used to stably transduce tumor cells with the LIGHT gene. A 1.9-kb NotI/SalI fragment containing the LIGHT cDNA was inserted into PG1SamEN, which was derived from the Moloney murine leukemia virus, and the LIGHT gene was under the transcription control of the LTR from the Moline murine leukemia virus. Generation of the retroviral packaging line was described previously (24). These packaging lines were grown and the retroviral supernatants were harvested and added to a $75 \%$ confluent flask of wild-type MDA-MB-231. After the retroviral infection, LIGHT-expressing MDA-MB-231 cells were selected with G418 and designated MDA-MB-231/LIGHT. All stable transfectants including MDA-MB-231/LIGHT, human TNF $\alpha$-expressing line MDA-MB-231/TNF $\alpha$, and the vector control line MDA-MB-231/ neo were grown and maintained in the presence of G418.

In vitro proliferation assays. Cells (5,000 cells/well) were plated in triplicate in 24-well plates with various amounts of LIGHT for $5 \mathrm{~d}$. The numbers of live cells were determined by trypan blue exclusion method. A soluble tetrazolium/formazan (XTT) assays were also performed: cells $(2,000-4,000$ cells/well) were seeded in the appropriate growth medium containing various amounts of LIGHT for $5 \mathrm{~d}$; XTT $(1.0 \mathrm{mg} / \mathrm{ml}$ plus PMS at $1.53 \mathrm{mg} / \mathrm{ml})$ was then added to each well and incubated for $4 \mathrm{~h}$ at $37^{\circ} \mathrm{C}$. Absorbance was measured with the Dynatech Model MR700 (Chantilly, VA).

Tumorigenicity studies. Female athymic Ncr-nu nude mice, 6 wk old, were obtained from Charles River Laboratories (Raleigh, NC). Various groups of MDA-MB-231 cells $\left(1 \times 10^{6}\right)$ were injected into the mammary fat pad of the nude mice. Mice were then ear tagged and randomized. Tumor size was assessed by measuring perpendicular diameters with a caliper twice weekly in a blinded fashion. Each group consisted of 10 animals, and the experiments were repeated three times.

Immunohistochemical analyses. Excised tumors were fixed in formalin and five micron sections were cut and mounted on Superfrost Plus slides. Sections were stained with hematoxylin and eosin (H\&E) or with GR-1 (Ly-6G), a rat anti-mouse mAb, which specifically recognizes neutrophils (PharMingen, San Diego, CA) according to the manufacturer's procedure. The amounts of $\mathrm{Gr}-1^{+}$neutrophils and the total tumor areas of each tumor were determined by the use of BioQuant-True image analysis system (R\&M Biometrics, Nashville, TN).

Production of the soluble LIGHT protein. The sequence encoding amino acids $74-240$ of LIGHT, i.e., the putative extracellular domain, but lacking the transmembrane and the cytoplasmic portions of LIGHT, was subcloned into the vector pFLAG/CMV-1. The pFLAG-sLIGHT plasmid was transiently transfected into $293 \mathrm{~T}$ cells to generate recombinant sLIGHT. Culture media from cells transfected pFLAG-sLIGHT were passed through anti-FLAG mAb affinity columns (Eastman Kodak, Rochester, NY). The column eluents were fractionated by SDS-PAGE and SLIGHT $(21 \mathrm{kDa})$ was detected by Western blot analysis using the anti-FLAG mAb.

Generation of receptor-Fc fusion proteins and the LT $\beta R$ and TR2/ HVEM antibodies. Production of TR2/HVEM-Fc fusion protein was previously described (11). For generating LT $\beta R-F c$ protein, the extracellular domain of human LT $\beta$ R gene was isolated by reverse transcription (RT)-PCR from HepG2 cells by using the forward primer 5'-CGGGATCCATGCTCCTGCCTTGGGCCAC and reverse primer: 5'-GCGGATCCTGGGGGCAGTGGCTCTAATGG. The amplified product was ligated in-frame into BglII-cut pUC19-IgG1-Fc vector containing the human IgG1 Fc. The fusion gene was then subcloned into pBacPAK9 vector (Clontech Co., Palo Alto, CA). The LT $\beta R-F c$ expressing pBacPAK9 vector was then cotransfected with linearized BacPAK6 DNA into Sf9 cells. The LT $\beta \mathrm{R}-\mathrm{Fc}$ protein containing supernatants from the recombinant virus infected Sf 21 cells were filtered and trapped onto protein A Sepharose beads; the bound LT $\beta R-F c$ protein was then eluted with glycine buffer ( $\mathrm{pH}$ 3.0) and followed by dialysis in PBS.

For generation of LT $\beta \mathrm{R} \mathrm{mAb}, \mathrm{BALB} / \mathrm{cJ}$ mice (Jackson Laboratory, West Grove, PA) were immunized and boosted three times with LT $\beta R-F c$ fusion proteins in Freund's adjuvant. The splenocytes were then fused with the murine myeloma NS-1 cells. Supernatants from positive wells were tested for the ability to bind LT $\beta \mathrm{R}-\mathrm{Fc}$ fusion protein by ELISA. The mAb to LT $\beta$ R-Fc were cloned by limiting dilution three times, then were subsequently purified from ascites by affinity chromatography. Similarly, using TR2/HVEM-GST fusion protein, the mAbs to human TR2/HVEM were screened by ELISA assays. The specificity of mAbs has been confirmed.

Flow cytometric analysis. Cells were harvested and incubated with either Flag-tagged LIGHT protein or various Abs at $10 \mu \mathrm{g} / \mathrm{ml}$ in the binding buffer for $30 \mathrm{~min}$ at $4^{\circ} \mathrm{C}$. Cells were then washed and stained with phycoerythrin conjugated to goat anti-mouse $\operatorname{IgG}$ at 20 $\mu \mathrm{g} / \mathrm{ml}$. To compete for cell surface binding, soluble LT $\beta R-F c$ or TR2/ HVEM-Fc at $10 \mu \mathrm{g} / \mathrm{ml}$ was preincubated with sLIGHT for $30 \mathrm{~min}$ before adding to cells. Fluorescence was analyzed by a FACScan ${ }^{\circledR}$ (Becton Dickinson, Mountain View, CA). To detect apoptosis of various cells treated with LIGHT, $10^{6}$ cells from each treatment group were incubated with Annexin V-FITC (Trevigen, Gaithersburg, MD) and propidium iodide at $4^{\circ} \mathrm{C}$ for $15 \mathrm{~min}$. The fluorescence of Annexin V-FITC and propidium iodide of individual cells were analyzed by FACScan ${ }^{\circledR}$.

Lymphokine release assay. The lymphokine release assays were performed to detect human PBMC reactivity with LIGHT as previously described (21). In brief, human PBMC cells were incubated for $5 \mathrm{~d}$ in the absence or presence of anti-CD3 $\mathrm{mAb}(10 \mathrm{ng} / \mathrm{ml})$ and rIL-2 $20 \mathrm{U} / \mathrm{ml}$ plus LIGHT protein at various concentrations, the secretion of IFN $\gamma$ was determined using ELISA kit from R\&D Systems Inc. (Minneapolis, MN).

\section{Results}

Chromosomal localization of LIGHT. The deduced amino acid sequence of the LIGHT cDNA predicted a putative polypeptide of 240 amino acids in length. It is a typical type-II transmembrane protein and shows 34 and $31 \%$ identity to lymphotoxin $\beta$ (LT $\beta)$ and FasL, respectively. The FISH mapping procedure was applied. Detailed analysis of six individual 
A
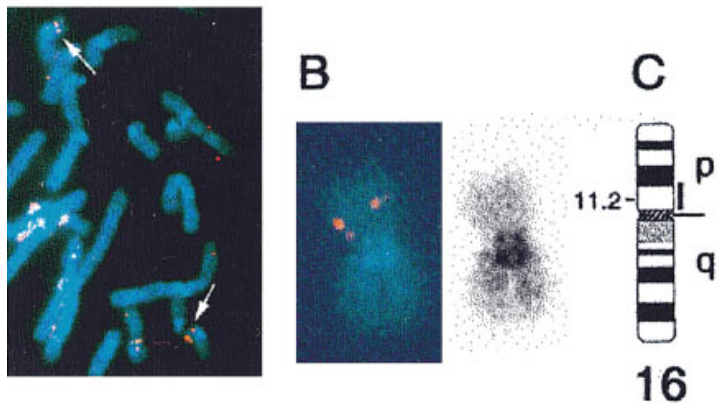

Figure 1. Fluorescence in situ hybridization mapping of the LIGHT gene. The LIGHT cDNA was hybridized to normal human male chromosomes. $(A)$ A chromosome spread from a single cell showing hybridization to the $\mathrm{p}$ arm of both chromosomes 16 (arrows). (B) Image of a single chromosome 16 (blue) with hybridization gene signal (red). (C) Idiogram of chromsome 16 showing the position (vertical bar) of the LIGHT gene.

chromosomes indicated that the LIGHT gene is located within band 16p11.2 (Fig. 1).

LIGHT is highly expressed in activated lymphocytes but not in cancer cells. Northern blot analyses indicated that LIGHT mRNA is $\sim 2.5 \mathrm{~kb}$ in length and is expressed predominantly in

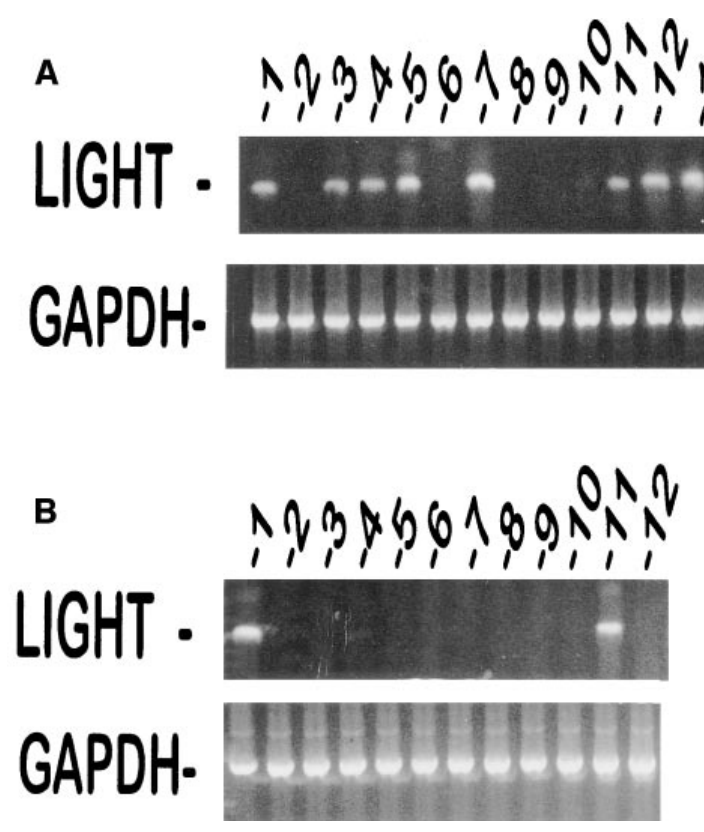

Figure 2. (A) RT-PCR analysis of LIGHT expression in various human hematopoietic cells: fresh PBL (lane 1), resting PBL \#1 (lane 2), activated PBL \#1 (lane 3 ), activated $\mathrm{CD}^{+}$T cells (lane 4), activated $\mathrm{CD}^{+} \mathrm{T}$ cells (lane 5), resting PBL \#2 (lane 6), activated PBL \#2 (lane 7), resting Jurkat cells (lane 8), activated Jurkat cells (lane 9), K562 (lane 10), TIL1200 (lane 11), TIL1235 (lane 12), granulocytes (lane 13), and monocytes (lane 14). (B) RT-PCR analysis of LIGHT expression in various human cancer cells: breast carcinoma cell lines MDA-MB-231/LIGHT (lane 1, positive control), MDA-MB-231/Wt (lane 2), MCF-7 (lane 3), MDA-134 (lane 4), BT-474 (lane 5), and MDA-361 (lane 6); human colon carcinoma cell lines HT-29 (lane 7), and SW-480 (lane 8); human prostate cancer cell lines PC-3 (lane 9), and LNCaP (lane 10); human breast epithelial line MCF-10A (lane 11), and human embryo kidney cell line $293 \mathrm{~T}$ (lane 12).
Table I. Expression of LIGHT, LT $\beta R$, or TR2/HVEM and the Effects of sLIGHT on the In Vitro Proliferation of Various Human Cells

\begin{tabular}{lcccc}
\hline \multicolumn{1}{c}{ Cell lines } & $\begin{array}{c}\text { LIGHT } \\
\text { expression* }\end{array}$ & $\begin{array}{c}\text { LT } \beta R \\
\text { expression* }\end{array}$ & $\begin{array}{c}\text { TR2/HVEM } \\
\text { expression* }\end{array}$ & $\begin{array}{c}\text { Growth } \\
\text { inhibition by } \\
\text { sLIGHT }^{\ddagger}\end{array}$ \\
\hline MDA-MB-231 & - & ++ & ++ & +++ \\
MCF-7 & - & ++ & ++ & ++ \\
HT-29 & - & +++ & ++ & +++ \\
HT3 & n.d. & ++ & + & ++ \\
PC-3 & - & ++ & - & - \\
PC-3/TR2/HVEM & - & ++ & ++ & ++ \\
293T & - & - & - & - \\
MCF-10A & ++ & + & + & - \\
PBMC & + & - & + & - \\
CD3+ T cells & + & - & ++ & - \\
TIL 1200 & + & - & + & - \\
Jurkat & - & - & + & - \\
& & & & \\
\hline
\end{tabular}

*Expression of LIGHT was determined by RT-PCR assay; expression of LT $\beta R$ and TR2/HVEM was determined by FACS analysis; n.d., not done. "Growth inhibition was carried out in the presence of LIGHT protein $(100 \mathrm{ng} / \mathrm{ml})$ plus INF $\gamma(10 \mathrm{U} / \mathrm{ml}):+, 30 \%$ inhibition;,$++ 50 \%$ inhibition;,$+++ 80 \%$ or more inhibition;,$-<10 \%$ inhibition. ${ }^{8}$ PC-3/TR $2 /$ HVEM cells were generated by stably transfected PC-3 cells with the full length of TR2/HVEM cDNA. Surface expression of TR2/HVEM on these cells was confirmed by FACS analysis. "LIGHT was found only in the activated PBMC, not in the resting PBMC.

spleen and peripheral blood lymphocytes (18, and data not shown). RT-PCR analyses were performed to study the expression patterns of LIGHT in various cells. As shown in Fig. 2 $A$, the LIGHT mRNA was detected from fresh PBMC, which includes a mixture of $\mathrm{T}$ and $\mathrm{B}$ lymphocytes, natural killer cells, monocytes and granulocytes (lane 1 ), which is consistent with Northern blot analysis. No LIGHT mRNA was found in resting PBMC (lanes 2 and 6), resting and activated Jurkat cells (lanes 8 and 9), or K562 cells (lane 10). Increased LIGHT mRNA was found in activated PBMC (lanes 3 and 7), $\mathrm{CD}^{+}$ and $\mathrm{CD}^{+}{ }^{+} \mathrm{T}$ cells (lanes 4 and 5), two $\mathrm{CD}^{+}$(TIL) cell lines (lanes 11 and 12), granulocytes (lane 13), and monocytes (lane 14). In addition, the presence of LIGHT mRNA was detected in LPS-activated neutrophils and PMA-stimulated U937 cells. There was little or nondetectable expression of LIGHT in various cancer cell lines derived from breast (MDA-MB-231, MCF-7, MDA-134, BT-474, and MDA-361), colon (HT-29 and SW-480), prostate (PC-3 and LNCaP), or 293T cells, except in one human breast epithelial-derived, nontumorigenic cell line MCF-10A cells (Fig. 2 B). In addition, no LIGHT was found in three breast cancer tissue samples examined (data not shown). Moreover, all lymphopoietic cells examined showed no expression of LT $\beta$ R, but TR2/HVEM was positive in all these cells, especially in activated Jurkat cells or PBMC (Table I). This is consistent with previous reports that peripheral lymphocytes do not express the LT $\beta R(23,24)$, while TR2/HVEM expression was associated with $\mathrm{T}$ cell activation (11).

Constitutive expression of LIGHT resulted in growth inhibition under serum starvation or treatment with IFN $\gamma$. To investigate the biological functions of LIGHT, the full-length LIGHT cDNA was stably transfected into the MDA-MB-231 

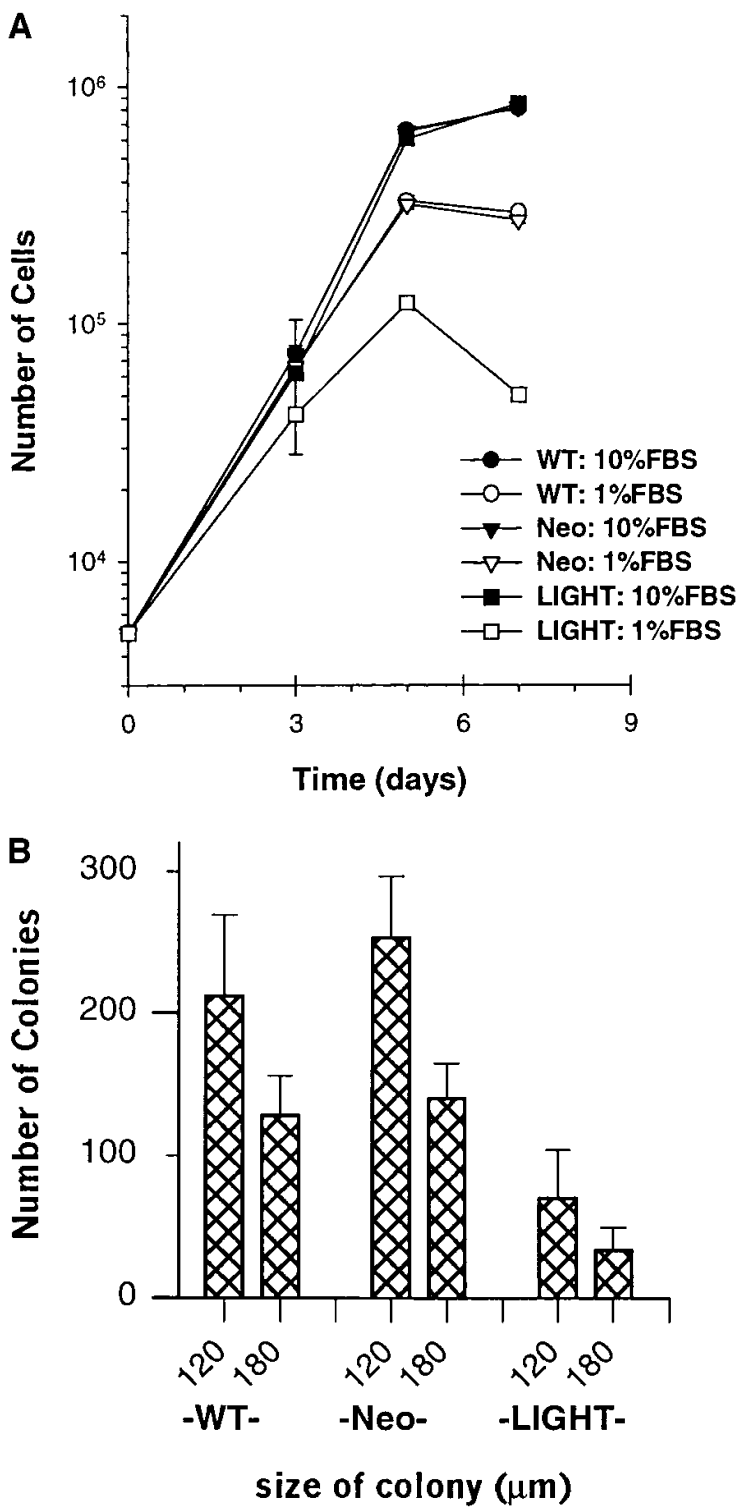

Figure 3. (A) Effect of LIGHT gene transfer on the in vitro proliferation of MDA-MB-231 cells. 5,000 MDA-MB-231/Wt (circles) or MDA-MB-231/neo (triangles) or MDA-MB-231/LIGHT (squares) cells were plated in triplicate in 24-well plates with IMEM in the presence of either $10 \%$ FBS (filled circle, triangle, or square) or $1 \%$ FBS (open circle, triangle, or square). The number of live cells was determined by trypan blue exclusion method at day 3,5 , or 7 . Cells were fed with fresh medium every $2 \mathrm{~d}$ during this time course. (B) Colony formation of MDA-MB-231/WT, MDA-MB-231/Neo, and MDAMB-231/LIGHT cells in $0.33 \%$ agarose. The average number of colonies at 120 or 180 micrometer $(\mu \mathrm{m})$ in diameter from three dishes per cell line determined by image analysis was shown.

cells by using a retroviral vector. Expression of the LIGHT gene was confirmed by Northern blot analysis. As predicted, transfection of a full-length LIGHT cDNA resulted in cell surface expression of a protein, which binds to both TR2/HVEM and LT $\beta$ R receptors as demonstrated by FACS ${ }^{\circledR}$ analysis (data not shown). No difference in the in vitro growth rate was observed among MDA-MB-231/LIGHT, parental cells MDAMB-231/Wt, and MDA-MB-231/Neo in the culture medium containing $10 \%$ FBS. However, when the serum concentration was reduced to $1 \%$, the proliferation of MDA-MB-231/ LIGHT cells was significantly inhibited compared with that of MDA-MB-231/Wt or MDA-MB-231/Neo cells (Fig. 3 A). A serum concentration-dependent growth inhibition was also observed in MDA-MB-231/LIGHT cells (data not shown).

An anchorage-independent growth inhibition of LIGHT expressing MDA-MB-231 cells was also confirmed in a soft agar colony assay. $80 \%$ reduction of colony formation was found in the MDA-MB-231/LIGHT cells as compared with that of the parental or vector control cells (Fig. 3 B). Furthermore, treatment of MDA-MB-231/LIGHT cells with $25 \mathrm{U} / \mathrm{ml}$ of IFN $\gamma$ also caused $80 \%$ growth inhibition, whereas in the parental or vector control cells, there was only $20-30 \%$ inhibition.

LIGHT expression induces apoptosis of the tumor cells. Annexin-V FACS analyses were performed to investigate underlying mechanisms of growth inhibition of LIGHT-transfected cells. There are $<2 \%$ apoptotic cells in all MDA-MB-231 parental and gene transferred cell lines in 10\% FBS (repeated three times with similar results; see also Fig. 5 B). After $72 \mathrm{~h}$ incubation in reduced serum (0.5\% FBS), the apoptotic MDAMB-231/LIGHT cells showed a threefold increase, up to $8 \%$, compared with that of MDA-MB-231/Wt cells. There was little or no increase of apoptosis in MDA-MB-231/Neo cells. In addition, coculture of MDA-MB-231/Wt or HT-29 cells with MDA-MB-231/LIGHT cells resulted in killing of the MDAMB-231/Wt or wild-type HT-29 cells in a direct coculture assay. More importantly, the conditioned medium from MDAMB-231/LIGHT cells showed marked inhibitory effect on in vitro proliferation of HT-29 cells, as compared with the conditioned media from MDA-MB-231/Wt or MDA-MB-231/Neo cells (data not shown). Thus, it appears that the natural LIGHT protein is indeed a secreted protein.

Potent in vivo antitumor activities of LIGHT gene therapy. We have evaluated the effects of LIGHT transfection on the tumor growth in vivo. When MDA-MB-231/LIGHT cells were inoculated into the mammary fat pads, LIGHT transfection significantly inhibited xenograft MDA-MB-231 tumor formation in nude mice, whereas the MDA-MB-231/TNF $\alpha$ or MDA-MB-231/Neo cells showed no change in tumor growth as compared with that of MDA-MB-231/Wt cells (Fig. $4 A$ ). Similar tumor suppression in the MDA-MB-231/LIGHT cells was also demonstrated in SCID mice (data not shown). Histological studies revealed that the parental or vector control MDA-MB-231 cells formed a large solid tumor mass filled predominantly with tumor cells with little cellular infiltrate (Fig. 4 $B)$. In contrast, there was extensive necrosis observed even in small residual tumors formed by the MDA-MB-231/LIGHT cells in nude mice (Fig. $4 \mathrm{~B}$ ). In addition, there was a significant increase in number of infiltrating neutrophil cells in LIGHT-expressing tumors (Fig. $4 \mathrm{~B}$ ); the average number of neutrophils (mean \pm SD) per square millimeter tumor size in wild-type, Neo control, and LIGHT-transduced MDA-MB-231 tumors were $101 \pm 26,77 \pm 16$, and $226 \pm 38$, respectively $(P<$ 0.01 ), based on the immunohistological staining using Gr-1 $\mathrm{mAb}$. Injection of LIGHT-expressing tumor cells did not cause gross abnormalities in the nude mice or SCID mice, such as weight loss or hepatic injury, during the experimental period. Our data suggest that locally producing LIGHT via gene transfer might exert a potent antitumor effect without inducing systemic toxicity.

The biological activities of the soluble LIGHT protein. A recombinant soluble LIGHT protein (sLIGHT) was produced 


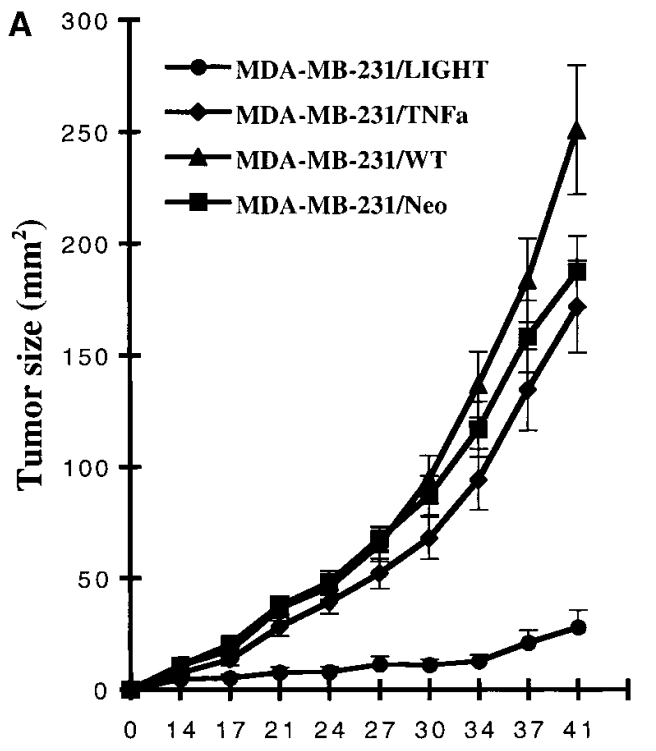

Days post-tumor injection
B

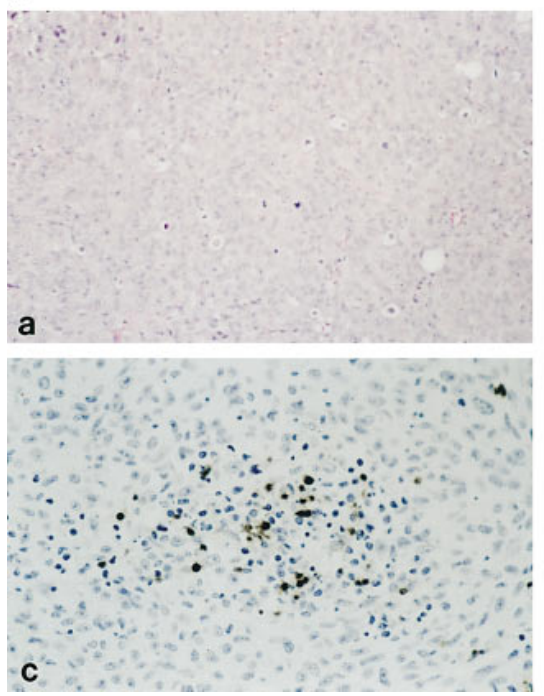

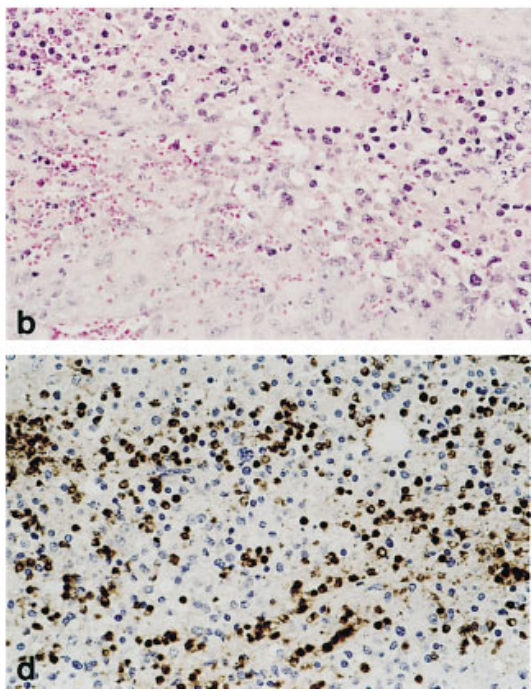

Figure 4. (A) Effects of LIGHT gene transfer on the growth of MDA-MB-231 human breast xenograft cancer in athymic nude mice. Female athymic nude mice were fat-pad injected with $10^{6}$ MDA-MB-231/Wt (filled triangle), MDA-MB-231/Neo (filled square), MDA-MB-231/TNF $\alpha$ (filled diamond), or MDA-MB-231/LIGHT (filled circle) cells. Each point represents mean number + SEM with ten mice per group. The experiment was repeated with similar results. (B) Histological examination of MDA-MB-231/Neo $(a$ and $c$ ) and MDA-MB-231/ LIGHT ( $b$ and $d$ ) human breast xenograft cancers. The tumor sections were stained with $\mathrm{H} \& \mathrm{E}$ ( $a$ and $b$ ), or by a rat anti-mouse mAb Gr-1, which specifically recognizes neutrophils visualized by brown staining $(c$ and $d) . \times 40$.

by transient transfecting $293 \mathrm{~T}$ cells with a construct of pFlagLIGHT and was purified with an anti-Flag $\mathrm{mAb}$. As shown in Fig. $5 \mathrm{~A}$, the sLIGHT protein inhibited the proliferation of MDA-MB-231 cells in a dose-dependent manner. The sLIGHT protein also caused morphological alterations in those cells, which is similar to the transfected MDA-MB-231/LIGHT cells. Addition of IFN $\gamma$ dramatically enhanced cytotoxicity of the sLIGHT protein, whereas IFN $\gamma$ alone showed little activity on the MDA-MB-231 cells (Fig. $5 \mathrm{~A}$ ), which is consistent with the previous report (25). In addition, sLIGHT-induced apoptosis of MDA-MB-231 cells in the presence of IFN $\gamma$, was demonstrated by annexin V-FACS analysis (Fig. $5 \mathrm{~B}$ ). Induction of apoptosis was more prominent in HT-29 cells treated with sLIGHT plus IFN $\gamma$, up to $80 \%$ (Fig. $5 C$ ).

We also tested a series of other normal and tumor cell lines for their sensitivities to the sLIGHT-mediated killing. As summarized in Table I, MDA-MB-231, MCF-7, HT-29, and HT-3 cell lines are sensitive to the sLIGHT, whereas 293T, PC-3, and MCF-10A are resistant to sLIGHT-mediated cell killing. Among all cell lines tested, HT-29 is the most sensitive with $\mathrm{IC}_{50}<1 \mathrm{ng} / \mathrm{ml}$. It has been shown that HT-29 was also very sensitive to $\mathrm{TNF} \alpha$-, Fas-, or $\mathrm{LT} \alpha_{1} \beta_{2}$-mediated killing in the presence of IFNy (26).

Involvement of both LTRR and TR2/HVEM for LIGHTinduced growth inhibition of cancer cells. The surface expression patterns of the LT $\beta R$ and TR2/HVEM in a series of human cancer cells were examined using the anti-LT $\beta R$ or anti-TR2/HVEM mAbs by FACS ${ }^{\circledR}$ analyses. As shown in Fig. $6 \mathrm{~A}$, high levels of both receptors were found on the MDAMB-231 and HT-29 cells, whereas PC-3 cells do not express TR2/HVEM, and Jurkat cells do not express LT $\beta R$ (Fig. $6 A$ ).
Table I summarizes also the surface expression patterns of both receptors in all cell lines examined. Interestingly, the cell lines, which express only one of the receptors, such as Jurkat or PC-3 cells, are resistant to the cytotoxicity of sLIGHT.

Several experiments were then conducted to further demonstrate the importance of both LT $\beta$ R and TR2/HVEM receptors in LIGHT-mediated tumor growth inhibition; FACS analyses were carried out using anti-Flag mAb. As shown in Fig. $6 \mathrm{~B}$, there was a positive shift in binding of MDA-MB-231 cells with the Flag-tagged sLIGHT protein. However, preincubation with LT $\beta R-F c$ or TR2/HVEM-Fc protein in the MDAMB-231 cells, the binding of sLIGHT protein to either LT $\beta R$ or TR2/HVEM receptors on the same cells was effectively blocked (Fig. 6 B).

We further tested whether LIGHT-induced growth inhibition was reversible by addition of the soluble TR2/HVEM-Fc or LT $\beta R-F c$ protein in HT-29 cells. As shown in Fig. $6 C$, the blockage of sLIGHT-mediated cytotoxicity in HT-29 by LT $\beta$ RFc or TR2/HVEM-Fc was in a dose-dependent manner, whereas the LT $\beta R-F c$ or TR2/HVEM-Fc itself showed no effect on inhibition of cell growth (Fig. $6 C$ ). In addition, in a similar assay, sLIGHT was unable to bind to other members of TNFR, such as TNFRI, Fas, DR3 (7) or DR4 (8; data not shown).

The wild-type PC-3 human prostate cancer cells, which express only the LT $\beta$, are resistant to the LIGHT-mediated killing. After the TR2/HVEM transfection, TR2/HVEM-expressing PC-3 cells were selected with zeocin and designated PC-3/ TR2/HVEM. Surface expression of TR2/HVEM on these cells was confirmed by FACS ${ }^{\circledR}$ analysis using the anti-TR2/HVEM $\mathrm{mAb}$. We then compared the cytotoxic effects of LIGHT 


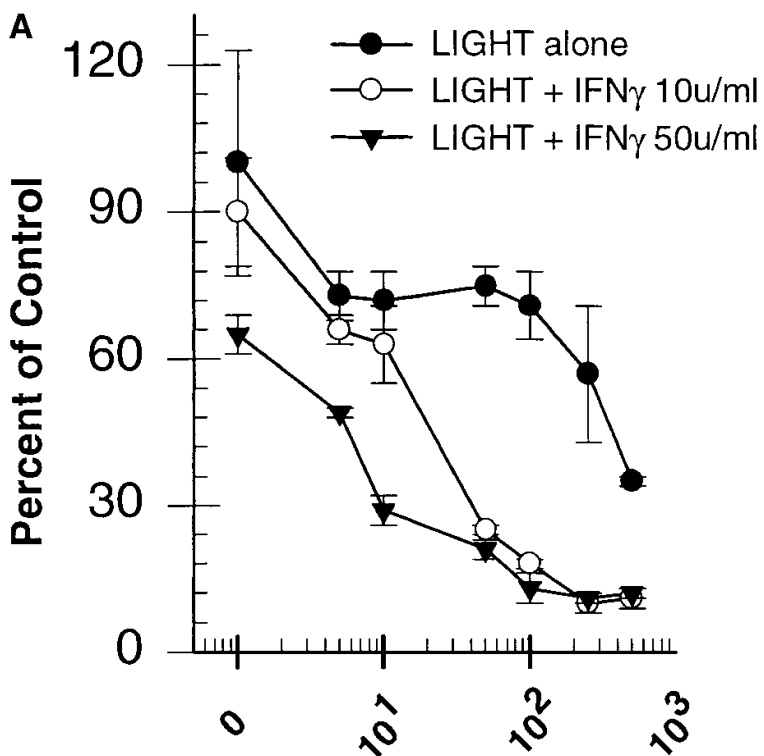

Concentration of sLIGHT (ng/ml)

C

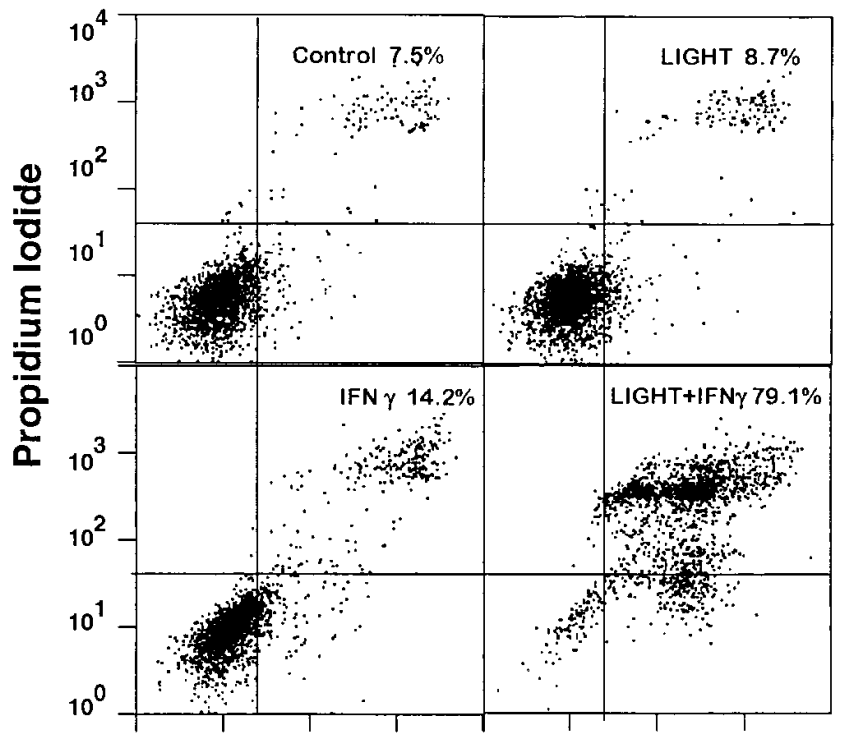

$$
\begin{array}{cccccc}
10^{0} \quad 10^{1} \quad 10^{2} \quad 10^{3} \quad 1^{0} \quad 10^{1} \quad 10^{2} \quad 10^{3} \\
\text { Annexin V }
\end{array}
$$

protein on PC-3 and PC-3/TR2/HVEM cells. Interestingly, the PC-3/TR2/HVEM cells, which expressed both LT $\beta$ R and TR2/HVEM receptors, showed $40-50 \%$ enhancement to LIGHT-induced growth inhibition than PC-3 cells, which expressed LT $\beta R$ only (Table I). The results directly support our working hypothesis that both TR2/HVEM and LTßR receptors are involved cooperatively in LIGHT-mediated killing of tumor cells.

Effects of LIGHT on lymphocytes. TIL1200 is a human CD8 ${ }^{+}$ $(99 \%)$ tumor infiltrating lymphocyte line (21) expressing a

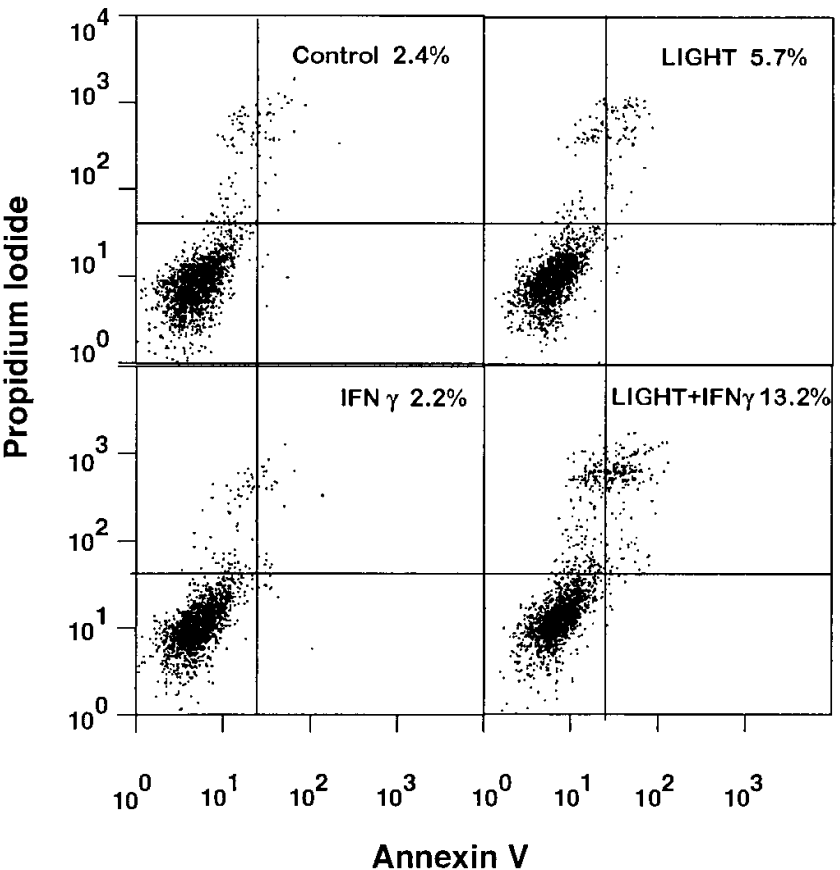

Figure 5. (A) Effects of the sLIGHT protein on proliferation of MDAMB-231 cells in the absence (filled circle) or presence of $10 \mathrm{U} / \mathrm{ml}$ (open circle) or $50 \mathrm{U} / \mathrm{ml}$ (filled triangle) of IFN $\gamma$, respectively. The assay was conducted as described in Methods. $(B)$ and $(C)$ LIGHT protein-induced apoptosis in MDA-MB-231 $(B)$ and HT-29 cells $(C)$. MDA-MB-231 or HT-29 cells were incubated with either control buffer, purified sLIGHT protein $(100 \mathrm{ng} / \mathrm{ml})$, or IFN $\gamma(10 \mathrm{U} / \mathrm{ml})$ alone or combination sLIGHT $(100 \mathrm{ng} / \mathrm{ml})$ and IFN $\gamma(10 \mathrm{U} / \mathrm{ml})$ for $72 \mathrm{~h}$. These cells were then analyzed by Annexin-V FACS ${ }^{\circledR}$ analysis.

high level of Fas. As shown in Fig. 7 A, no induction of apoptosis was found in TIL1200 cells treated with sLIGHT alone or in the presence of IFN $\gamma$. In the coculture experiments of TIL1200 cells along with the MDA-MB-231/LIGHT cells, membrane-bound LIGHT also did not induce apoptosis of TIL1200, whereas the addition of Fas mAb triggered $60 \%$ of TIL1200 undergone apoptosis (data not shown).

In addition, we screened several hematopoietic cell lines and PBMC for their responsiveness to the sLIGHT-mediated cytotoxicity. No cytotoxic effect of LIGHT was observed on 

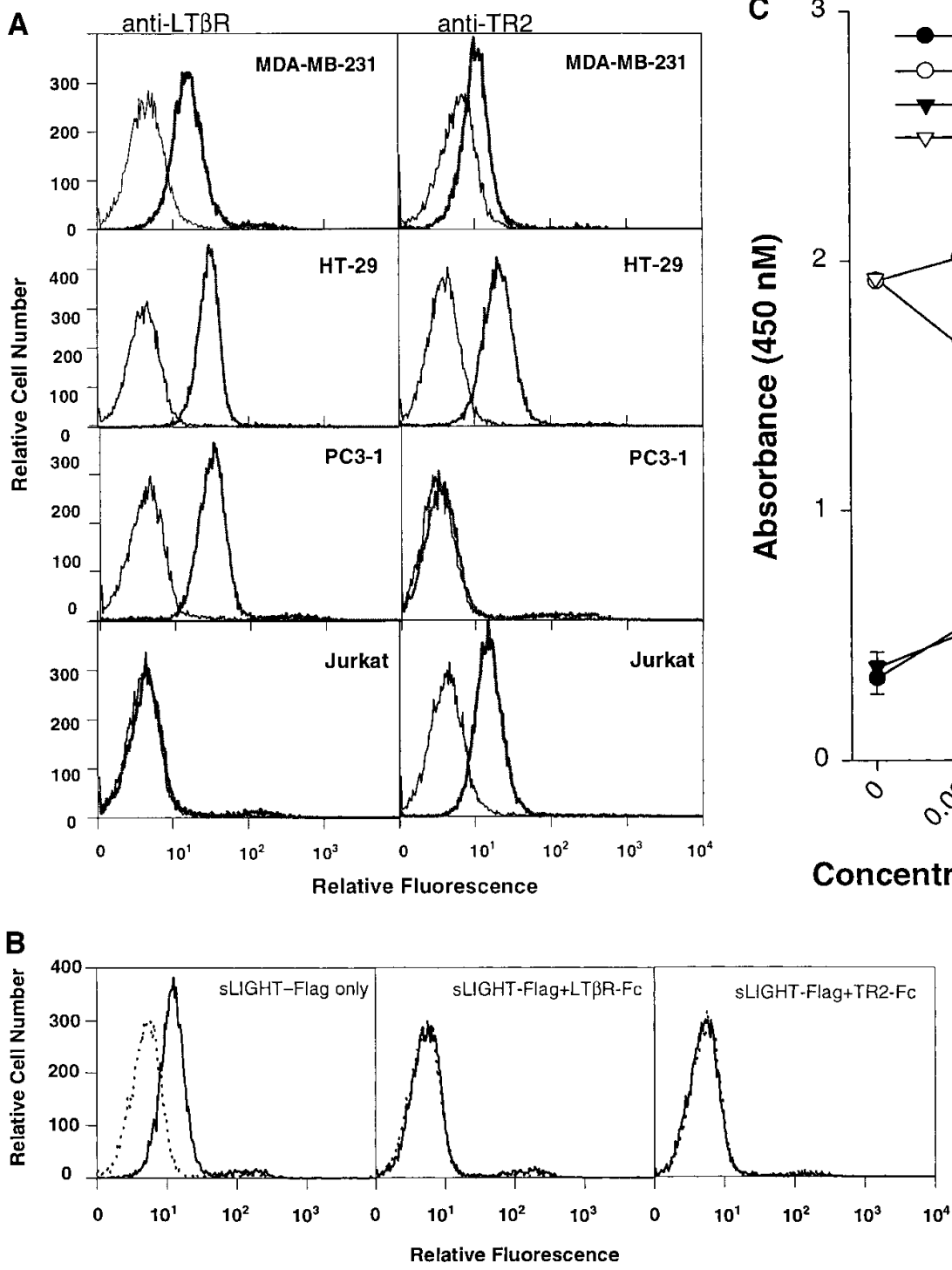

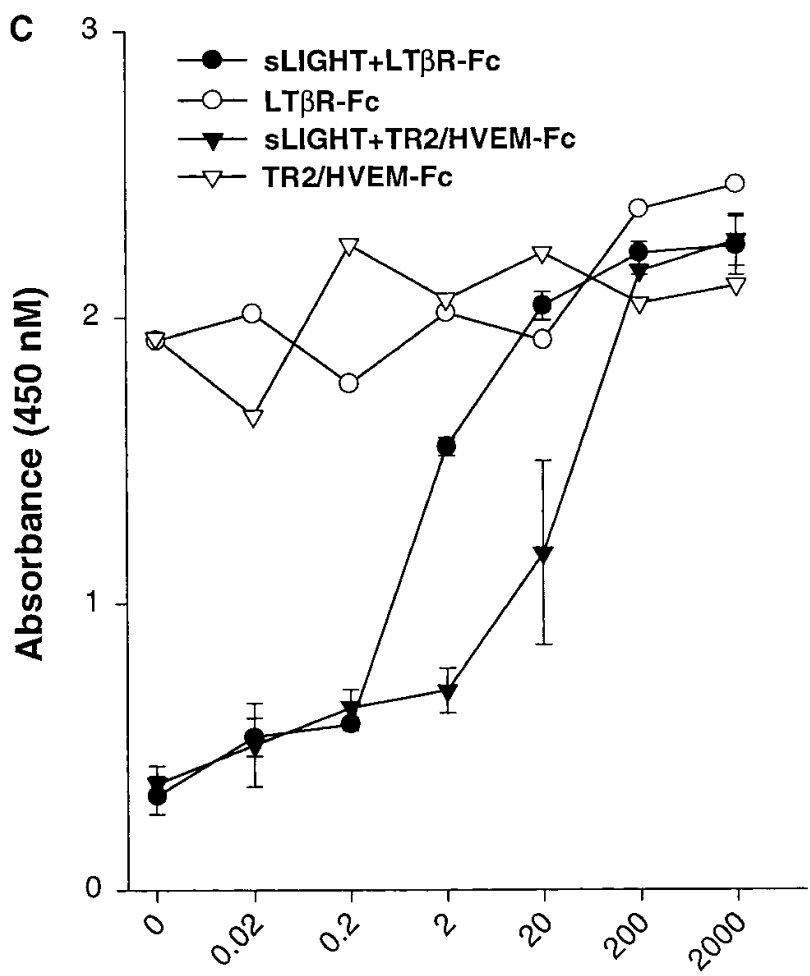

Concentration of Soluble Receptor (ng/ml)

Figure 6. (A) Surface expression of the LT $\beta$ R or the TR2/HVEM receptors in various human tumor cells by $\mathrm{FACS}^{\circledR}$ analysis using anti-LT $\beta \mathrm{R}$ or antiTR2/HVEM mAb, respectively. $(B)$ FACS $^{\circledR}$ binding analysis of a sLIGHT protein alone and blocking of a soluble LIGHT protein binding by preincubating with the LT $\beta R-F c$ fusion protein or TR2/ HVEM-Fc fusion protein in MDA-MB-231 cells. (C) Effects of LT $\beta$ R-Fc or TR2/HVEM-Fc fusion protein on blocking the sLIGHT-mediated cytotoxicity in HT-29 cells. Cells were incubated either with various doses of soluble LT $\beta$ R-Fc alone

(open circle) or TR2/HVEM-Fc alone (open triangle) or with sLIGHT $(10 \mathrm{ng} / \mathrm{ml}) \mathrm{plus} 5 \mathrm{U} / \mathrm{ml}$ of IFN $\gamma$ in the presence of various amounts of LT $\beta$ R-Fc (filled circle) or TR2/HVEM-Fc (filled triangle) as indicated for $5 \mathrm{~d}$. The viability of treated cells was then determined by the XTT assay.

either resting or CD3 mAb-activated Jurkat cells, K562 cells, $\mathrm{CD}^{+}, \mathrm{CD}^{+}$PBLs, $\mathrm{CD} 8^{+}$TIL1200 or the fresh or activated PBMC (Table I). In contrast, treatment of the activated PBMC with sLIGHT, resulted in release of IFN $\gamma$ from these TR2/HVEM-expressing cells as demonstrated by ELISA assay (Fig. 7 B).

\section{Discussion}

We have characterized the biological functions of LIGHT and its possible mechanisms of action as a novel ligand for LT $\beta R$ and/or TR2/HVEM. The data have demonstrated that LIGHT exhibits cytotoxicity primarily in tumor cells, while at the same time stimulating secretion of IFN $\gamma$ from the activated PBL.

LIGHT was originally identified from a human-activated $\mathrm{T}$ cell library by homology search with the TNF and TNFR family. Like other TNF-related ligands, LIGHT is a type-II transmembrane protein with $\mathrm{C}$ terminus on the exterior cell surface, a single transmembrane domain, and a short cytoplasmic tail (18). Treatment of MDA-MB-231 human breast carcinoma cells with LIGHT, in conjunction with serum starvation or addition of IFN $\gamma$, resulted in inhibition of cell proliferation. The enhanced apoptosis of the tumor cells, as demonstrated by Annexin-V FACS ${ }^{\circledR}$ analysis and DNA fragmentation (data not shown), appears to be the primary cause for the LIGHT-mediated growth inhibition in vitro. Interestingly, LIGHT-induced growth inhibition of the LT $\beta R$ and TR2/HVEM expressing MDA-MB-231 and HT-29 cells took place quite slowly, i.e., at least 3-5 d. Substantial cell lysis does not occur even after 4-5 d for some cell lines. The results indicated that the dynamics of action of the LIGHT protein are similar to the effect of LT $\alpha_{1} \beta_{2}$ heterotrimers (20). Browning et al. (20) have shown that Fas activation led to rapid cell death (12-24 h); TNF $\alpha$ requires $24 \mathrm{~h}$ whereas $\mathrm{LT} \alpha_{1} \beta_{2}$ takes 2-3 d in induction of apoptosis for HT-29 cells.

The biological activities of LIGHT in vitro and in vivo are clearly distinguishable from other known members of the TNF family. First, unlike genes encoding other known TNF ligands 


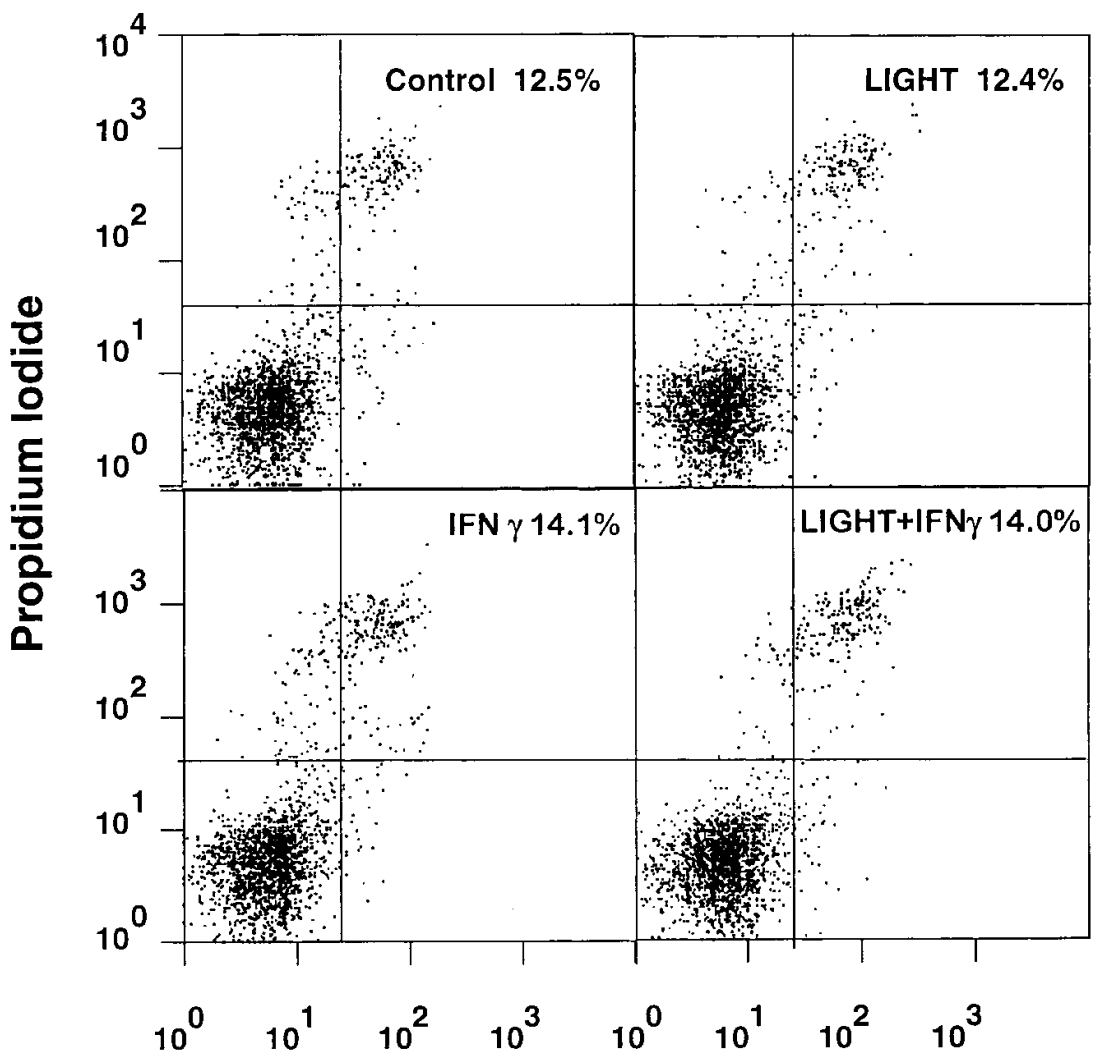

Annexin V

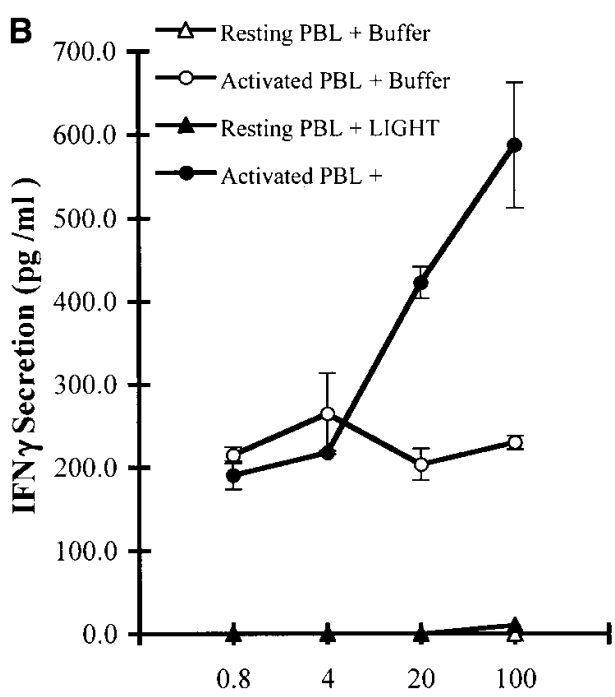

LIGHT concentrations $(\mathrm{ng} / \mathrm{ml})$

Figure 7. (A) Effect of LIGHT protein on inducing apoptosis of TIL1200 cells. TIL1200 cells were preincubated with control buffer, IFN $\gamma(10$ $\mathrm{U} / \mathrm{ml})$ alone, purified sLIGHT protein $(100 \mathrm{ng} / \mathrm{ml})$ in the absence or presence of IFN $\gamma(10 \mathrm{U} / \mathrm{ml})$ for $48 \mathrm{~h}$. These cells were then harvested and analyzed by Annexin V staining. (B) Secretion of IFN $\gamma$ by the activated human PBL treated with the sLIGHT protein. Human PBLs $\left(5 \times 10^{5}\right.$ cells per well in the 96-well plate) were treated with or without anti-CD3 mAb $(100 \mathrm{ng} / \mathrm{ml})$ and IL-2 (10 U/ml) in the presence or absence of sLIGHT for $5 \mathrm{~d}$. The supernatants were then harvested from the following groups of cells: the activated PBLs in the presence (filled circle) or absence (open circle) of sLIGHT or the resting PBL with (filled triangle) or without (open triangle) sLIGHT. Human IFN $\gamma$ concentration was determined by ELISA.

such as TNF $\alpha$, LT $\alpha$ and LT $\beta$ are tightly linked on human chromosome 6 within the MHC sandwiched between the class III and HLA-B locus (26). FISH-localized LIGHT gene to human chromosome 16p11.2, suggesting the different physiological functions of LIGHT from other TNF ligands. Second, both LT $\beta R$ and TR2/HVEM receptors lack the death domain in its cytoplasmic region, and thus engaging LIGHT to both LTRR and TR2/HVEM is intriguing. Although LT $\beta R$ and TR2/ HVEM could activate common signaling pathways via association with TNFR-associated factors (TRAFs) such as TRAF1, TRAF2, TRAF3, and TRAF5 $(12,13,25,27)$, signaling of LIGHT through the LT $\beta R$ and/or TR2/HVEM is unknown. Our data indicate that LIGHT-LT $\beta$ R and/or LIGHT-TR2/ HVEM interactions may trigger the distinct biological events. First, the death signaling of LIGHT may require the involvement of dual receptors, which was not previously reported. Several lines of our experimental evidence support this notion: (1.) LIGHT leads to the death of the cells expressing both LT $\beta R$ and TR2/HVEM but not the cells expressing only the LT $\beta R$ or the TR2/HVEM receptor as shown in Table I. The cytotoxic effect of LIGHT was dramatically enhanced in the presence of IFN $\gamma$; (2.) LIGHT-mediated cytotoxicity could be blocked specifically by addition of soluble LT $\beta$ R-Fc or a TR2/ HVEM-Fc in a dose-dependent manner; (3.) TR2/HVEM transfection of the wild type of PC-3 cells, which express LT $\beta R$ only, resulted in generation of the PC-3/TR2/HVEM cells, which expresses both LT $\beta$ R and TR2/HVEM receptors confirmed by FACS ${ }^{\circledR}$. Correspondingly, 40-50\% enhancement of LIGHT-induced cytotoxicity was observed in PC-3/TR2/ HVEM cells. Taken together, our data suggest that both LT $\beta R$ and TR2/HVEM receptors are involved in LIGHTmediated growth inhibition of tumor cells, expression of only one of these receptors might not be sufficient to trigger LIGHT-mediated cell killing. It remains to be elucidated whether both LIGHT-LT $\beta$ R and LIGHT-TR2/HVEM signaling contributes equally for the LIGHT-mediated cytotoxicity in tumor cells. We also can not exclude the possibility that LIGHT interacts with other known or unknown death receptors, although soluble LIGHT does not bind to Fas, DR3, DR4, or DR5 in the in vitro binding assays.

Second, the stimulatory signal of LIGHT might require the engagement of LIGHT to the TR2/HVEM receptor. LIGHT triggers the secretion of IFN $\gamma$ from the activated PBMC, which express only the TR2/HVEM receptor as demonstrated 
in Fig. $7 \mathrm{~B}$. Since the TR2/HVEM cytoplasmic tail does not contain the death domain found in the Fas and TNFR intracellular domains, and appears more related to those of CD40 and 4-1BB. Signals through 4-1BB and CD40 have been shown to be costimulatory to $\mathrm{T}$ cells and B cells, respectively $(2,29)$. Our finding is consistent with the previous observation that a TR2/ HVEM-Fc fusion protein inhibited a mixed lymphocyte reaction-mediated proliferation (11). Moreover, all TR2/HVEMpositive hematopoietic cells tested are resistant to LIGHTmediated cell killing (Table I). Thus, our data suggest that LIGHT-TR2/HVEM signaling alone does not mediate death signal but presumably elicits costimulatory responses of the host immune system.

The dual signaling hypothesis of LIGHT is further supported by the distinct tissue and cell expression patterns of LT $\beta R$ and TR2/HVEM. It is known that LT $\beta R$ is expressed in various tumor lines, but it is absent on T and B lymphocytes (19, 20). The LT $\beta R$ is implicated as a critical element in controlling lymph node development and cellular immune reactions. Activation of LT $\beta$ R by using recombinant $\mathrm{LT} \alpha_{1} \beta_{2}$ heterotrimers or by cross-linking with immobilized antibodies, induces the death of adenocarcinoma cell lines and production of chemokine IL-8 and RANTES $(20,30)$. LT $\beta R$ induces apoptosis probably through the activation of TRAF3-dependent pathway (27). In contrast, TR2/HVEM mRNA is expressed in multiple human tissues and shows a constitutive and relatively high expression in hematopoietic lineage cells, including resting and activated $\mathrm{CD}^{+}$, or $\mathrm{CD}^{+}{ }^{+}$and $\mathrm{CD} 8^{+} \mathrm{T}$ cells, B cells, monocytes, and neutrophils (11). Hence, LIGHT probably has critical roles in induction of apoptosis and immune modulation; thus it may have the therapeutic potential as an anticancer agent.

It is worthwhile to mention that the antitumor effects of LIGHT gene therapy were demonstrated in both nude (low T but normal B cell activities) and SCID (no T and B cell activities) mice. A lack of correlation between the host $\mathrm{T}$ cell immunocompetence and tumorigenicity suggest that the $\mathrm{T}$ cellmediated tumor-specific response may not be an essential factor for the primary tumor rejection in the xenogeneic tumor model tested. However, the effect of LIGHT gene transfer on tumor suppression was also confirmed in an immune competent syngeneic murine tumor model. Local production of LIGHT in MC-38 murine colon cancer cells resulted in complete suppression in C57BL/6 mice (Zhai et al., unpublished data). The in vivo antitumor effects of LIGHT gene therapy presumably by potentiating both tumor-specific and nonspecific immune responses. Since the antitumor activity of LIGHT was demonstrated by local production of the protein via gene transfer, further studies with administration of LIGHT protein in vivo (which is not currently available) would be necessary to support this conclusion.

The dose-limiting toxicity of TNF $\alpha$ and the cytotoxicity of FasL for $\mathrm{T}$ cells limit their clinical applications as anticancer agents $(1-4,6)$. LIGHT could be an alternatively attractive approach since the LIGHT signaling is peculiar in at least two aspects: LIGHT would selectively induce death of tumor cells in a molecular context with both LT $\beta$ R and TR2/HVEM; at the same time, LIGHT might trigger the costimulatory signal rather than the death signal to lymphocytes expressing the TR2/HVEM. More importantly, LIGHT provides a novel system, distinct from the previously defined TNF or Fas system, for the further understanding of the signaling pathways of TNF ligand-receptor interactions.

\section{Acknowledgments}

We thank Gianni Garotta for critical reading and helpful comments and An-Guo $\mathrm{Wu}$ for the technical assistance on culturing the human hematopoietic cells.

FACS $^{\circledR}$ analysis was supported in part by National Cancer Institute CCSG grant to Lombardi Cancer Center (CA51008).

\section{References}

1. Smith, C.A., T. Farrah, and R.G. Goodwin. 1994. The TNF receptor superfamily of cellular and viral proteins: activation, costimulation, and death. Cell. 76:959-962.

2. Tewari, M., and V.M. Dixit. 1996. Recent advances in tumor necrosis factor and CD40 signaling. Curr. Opin. Genet. Dev. 6:39-44.

3. Aggarwal, B.B., and K. Natarajan. 1996. Tumor necrosis factors: developments during the last decade. Eur. Cytokine Netw. 7:93-124.

4. Baker, S.J., and E.P. Reedy. 1996. Transducers of life and death: TNF receptor superfamily and associated proteins. Oncogene. 12:1-9.

5. Chinnaiyan, A.M., and V.M. Dixit. 1997. Portrait of an executioner: the molecular mechanism of FAS/APO-1-induced apoptosis. Semin. Immunol. 9: 69-76.

6. Depraetere, V., and P. Golstein. 1997. Fas and other cell death signaling pathways. Semin. Immunol. 9:93-107.

7. Chinnaiyan, A.M., K. O'Rourke, G.L. Yu, R.H. Lyons, M. Garg, D.R Duan, L. Xing, R. Gentz, J. Ni, and V.M. Dixit. 1996. Signal transduction by DR3, a death domain-containing receptor related to TNFR-1 and CD95. Science. 274:990-992.

8. Pan, G., J. Ni, Y. Wei, G. Yu, R. Gentz, and V.M. Dixit. 1997. An antag onist decoy receptor and a death domain-containing receptor for TRAIL. Science. 277:815-818.

9. Pan, G., K. O'Rourke, A.M. Chinnaiyan, R. Gentz, R. Ebner, J. Ni, and V.M. Dixit. 1997. The receptor for the cytotoxic ligand TRAIL. Science. 276: 111-113.

10. Sheridan, J.P. S.A. Marters, R.M. Pitti, A. Gurney, M. Skubatch, D. Baldwin, L. Ramakrishnan, C.L. Gray, K. Baker, W.I. Wood, et al. 1997. Control of TRAIL-induced apoptosis by a family of signaling and decoy receptors. Science. 277:818-821.

11. Kwon, B.S., K.B. Tan, J. Ni, K.O. Lee, K.K. Kim, Y.J. Kim, S. Wang, R. Gentz, G.L. Yu, J. Harrop, et al. 1997. A newly identified member of the tumor necrosis factor receptor superfamily with a wide tissue distribution and involvement in lymphocyte activation. J. Biol. Chem. 272:14272-14276.

12. Montgomery, R.I., M.S. Warner, B.J. Lum, and P.G. Spear. 1996. Herpes simplex virus- 1 entry into cells mediated by a novel member of the TNF/ NGF receptor family. Cell. 87:427-436.

13. Hsu, H., I. Solovyev, A. Colombero, R. Elliott, M. Kelley, and W.J. Boyle. 1997. ATAR, a novel tumor necrosis factor receptor family member, signals through TRAF2 and TRAF5. J. Biol. Chem. 272:13471-13474.

14. Simonet, W.S., D.L. Lacey, C.R. Dunstan, M. Kelley, M.S. Chang, R. Luthy, H.Q. Nguyen, S. Wooden, L. Bennett, T. Boone, et al. 1997. Osteoprotegerin: a novel secreted protein involved in the regulation of bone density. Cell. 89:309-319.

15. Wiley, S.R., K. Schooley, P.J. Smolak, W.S. Din, C.P. Huang, J.K Nicholl, G.R. Sutherland, T.D. Smith, C. Rauch, C.A. Smith, et al. 1995. Identification and characterization of a new member of the TNF family that induces apoptosis. Immunity. 3:673-682.

16. Pitti, R.M., S.A. Marsters, S. Ruppert, C.J. Donahue, A. Moore, and A. Ashkenazi. 1996. Induction of apoptosis by Apo-2 ligand, a new member of the tumor necrosis factor cytokine family. J. Biol. Chem. 271:12687-12690.

17. Adams, M.D., A.R. Kerlavage, R.D. Fleischmann, R.A. Fuldner, C.J. Bult, N.H. Lee, E.F. Kirkness, K.G. Weinstock, J.D. Gocayne, O. White, et al. 1995. Initial assessment of human gene diversity and expression patterns based upon 83 million nucleotides of cDNA sequence. Nature. 377:3-174.

18. Mauri, D.N., R. Ebner, K.D. Kochel, R. Montgomery, T.C. Cheung, G.L. Yu, S. Ruben, M. Murphy, R.J. Eisenberg, G.H. Cohen, et al. 1998. LIGHT, a new member of the TNF superfamily, and lymphotoxin are ligands for herpesvirus entry mediator. Immunity. 8:21-30.

19. Crowe, P.D., T.L. Van Arsdale, B.N. Walter, C.F. Ware, C. Hession, B. Ehrenfels, J.L. Browning, W.S. Din, R.G. Goodwin, and C.A. Smith. 1994. A lymphotoxin-beta-specific receptor. Science. 264:707-710.

20. Browning, J., K. Miatkowski, I. Sizing, D. Griffiths, M. Zafari, C.D. Benjamin, W. Meier, and F. Mackay. 1996. Signaling through the lymphotoxin $\beta$ receptor induces the death of some adenocarcinoma tumor lines. J. Exp. Med. 183:867-878.

21. Zhai, Y., J.C. Yang, Y. Kawakami, P. Spiess, S.C. Wadsworth, L.M. Cardoza, L.A. Couture, A.E. Smith, and S.A. Rosenberg. 1996. Antigen-specific tumor vaccines: development and characterization of recombinant adenoviruses encoding MART1 or gp100 for cancer therapy. J. Immunol. 156:700-710.

22. Johnson, C.V., R.H. Singer, and J.B. Lawrence. 1991. Fluorescent detection of nuclear RNA and DNA: implications for genome organization. Meth. 
Cell Biol. 35:73-99.

23. Johnson, C.V., J.A. McNeil, K.C. Carter, and J.B. Lawrence. 1991. A simple, rapid technique for precise mapping of multiple sequences in two colors using a single optical filter set. Genet. Anal. Tech. Appl. 8:75-76.

24. Markowitz, D., S. Goff, and A. Bank. 1988. A safe packaging line for gene transfer: separating viral genes on two different plasmids. J. Virol. 62: $1120-1124$

25. Mueller, H., N. Flury, F. Liu, S. Scheidegger, and U. Eppenberger. 1996. Tumor necrosis factor and interferon are selectively cytostatic in vitro for hormone-dependent and hormone-independent human breast cancer cells. Eur. J. Cancer. 32A:2312-2318.

26. Browning, J L., A. Ngam-ek, P. Lawton, J. DeMarinis, R. Tizard, E.P. Chow, C. Hession, B. O'Brine-Greco, S.F. Foley, and C.F. Ware. 1993. Lymphotoxin beta, a novel member of the TNF family that forms a heteromeric complex with lymphotoxin on the cell surface. Cell. 72:847-856.

27. VanArsdale, T.L., S.L. VanArsdale, W.R. Force, B.N. Walter, G. Mo- sialos, E. Kieff, J.C. Reed, and C.F. Ware. 1997. Lymphmotoxin- $\beta$ receptor signaling complex: role of tumor necrosis factor receptor-associated factor 3 recruitment in cell death and activation of nuclear factor кB. Proc. Natl. Acad. Sci. USA. 94:2460-2465.

28. Marsters, S.A., T.M. Ayres, M. Skubatch, C.L. Gray, M. Rothe, and A. Ashkenazi. 1997. Herpesvirus entry mediator, a member of the tumor necrosis factor receptor (TNFR) family, interacts with members of the TNFR-associated factor family and activates the transcription factors NF-kB and AP-1. $J$. Biol. Chem. 272:14029-14032.

29. Hurtado, J., Y.J. Kim, and B.S. Kwon. 1997. A safe packaging line for gene transfer: separating viral genes on two different plasmids. J. Immunol. 158 2600-2609.

30. Degli-Eposti, M.A., T. Davis-Smith, W.S. Din, P.J. Smolak, R.G. Goodwin, and C.A. Smith. 1997. Activation of the lymphomitoxin $\beta$ receptor by cross-linking induces chemokine production and growth arrest in A375 melanoma cells. J. Immunol. 158:1756-1762. 